\title{
Posterior hypothalamus-sparing surgery improves outcome after childhood craniopharyngioma
}

\author{
Agnieszka Bogusz ${ }^{1,2}$, Svenja Boekhoff ${ }^{1}$, Monika Warmuth-Metz ${ }^{3}$, Gabriele Calaminus ${ }^{4}$, Maria Eveslage ${ }^{5}$ and \\ Hermann L Müller ${ }^{1, *}$ \\ ${ }^{1}$ Department of Pediatrics and Pediatric Hematology/Oncology, University Children's Hospital, Klinikum Oldenburg AöR, Oldenburg, Germany \\ 2Department of Endocrinology and Diabetology, The Children's Memorial Health Institute, Warsaw, Poland \\ ${ }^{3}$ Department of Neuroradiology, University Hospital, Würzburg, Germany \\ ${ }^{4}$ Department of Pediatric Oncology and Hematology, University Hospital, Bonn, Germany \\ Institute of Biostatistics and Clinical Research, University of Münster, Münster, Germany
}

Correspondence should be addressed to H L Müller: mueller.hermann@klinikum-oldenburg.de

*(H L Müller on behalf of the KRANIOPHARYNGEOM 2007 Study Committee)

\begin{abstract}
Objective: Quality of life (QoL) is frequently impaired in childhood-onset craniopharyngioma (CP) by hypothalamic syndrome. The debate, whether pretreatment hypothalamic involvement $(\mathrm{HI})$ has apriori prognostic impact or surgical hypothalamic lesions (HL) determine outcome, is controversial.

Design: Survival and outcome of CPs recruited between 2007 and 2014 in KRANIOPHARYNGEOM 2007 were analyzed with regard to reference-confirmed presurgical $\mathrm{HI}$ and surgical $\mathrm{HL}$.

Methods: Radiological findings, BMI and QoL were assessed at diagnosis and during follow-up. QoL was assessed using Pediatric Quality of Life (PEDQOL) questionnaire. Results: One hundred sixty-nine CPs were included presenting with no $\mathrm{HI}(n=11)$, anterior $(n=49)$ and anterior + posterior $(a+p) \mathrm{HI}(n=109)$ prior to surgery. The latter 109 were analyzed for postoperative HL (no lesion: $n=23$, anterior HL: $n=29, \mathrm{a}+\mathrm{pHL}: n=57$ ). Progression-free survival (PFS) was higher after complete resection. The highest PFS was observed in $\mathrm{CP}$ with a $+\mathrm{pHL}$, especially when compared between non-irradiated subgroups $(P=0.006)$. Overall survival $(O S)$ rates were 1.0 in all subgroups. CP with a + pHL developed higher BMI $(P \leq 0.001)$ during follow-up compared between subgroups. $55 / 109$ pts with $a+p H I$ completed PEDQOL at diagnosis (48/109 at 3 years follow-up). QoL was worse for a + pHL patients in terms of physical, social and emotional functionality when compared with the anterior $\mathrm{HL}$ and no $\mathrm{HL}$ subgroup. BMI development and QoL during follow-up were similar for patients with anterior $\mathrm{HL}$ and without $\mathrm{HL}$. Conclusions: Posterior hypothalamus-sparing surgical strategies are associated with higher QoL, decreased development of obesity and lower PFS in CP.
\end{abstract}

\section{Key Words}

- craniopharyngioma

- hypothalamus

- obesity

- quality of life

- surgery

\section{Introduction}

Craniopharyngiomas (CPs) are rare, histologically benign (WHO $\mathrm{I}^{\circ}$ ), embryonal malformations of the sellar/ parasellar area originating from neoplastic transformation of ectodermal-derived epithelial cell remnants of Rathke's pouch and the craniopharyngeal duct $(1,2$, $3,4,5,6)$. Overall survival (OS) rates after CP are high https://ec.bioscientifica.com https://doi.org/10.1530/EC-19-0074 (c) 2019 The authors Published by Bioscientifica Ltd

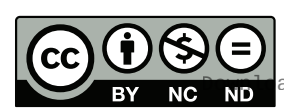

This work is licensed under a Creative Commons Attribution-NonCommercial-NoDerivatives 4.0 Internationab ticense.ifica com at $04 / 26 / 2023$ 10:15:41AM 
(87-95\% 20-year OS) (7). However, in long-term survivors, Quality of life (QoL) is frequently reduced due to morbidity caused by close anatomical proximity of $\mathrm{CP}$ to hypothalamic-pituitary axes $(8,9,10)$. Improvements of prognosis in terms of QoL and progression-free survival (PFS) will only be achieved by multidisciplinary, riskadapted neurosurgical and radiooncological treatment strategies, which provide appropriate medical and psychosocial support for CP patients $(11,12,13)$.

Disease-related and/or surgical hypothalamic lesions (HL) are associated with clinically significant impairments of OS and long-term QoL. However, the debate whether primary hypothalamic involvement $(\mathrm{HI})$ has major and apriori impact on prognosis and outcome or whether treatment-related, surgical HL is the determining risk factor for sequelae is controversial.

Accordingly, we prospectively analyzed a large cohort of CP patients with initial preoperative involvement of anterior and posterior $(\mathrm{a}+\mathrm{p})$ hypothalamic structures for postoperative QoL, BMI and functional capacity with regard to reference-confirmed degree of surgical hypothalamic damage.

\section{Patients and methods}

\section{Patients}

Overall, 178 (94 females/84 males) diagnosed with adamantinomatous CP (median age at diagnosis: 9.3 years, range: 1.3-17.9 years) were recruited between 2007 and 2014 in our multinational trial KRANIOPHARYNGEOM 2007 (NCT00258453) (14) and observed prospectively during follow-up of at least 3 years.

The degree of initial presurgical HI could be reference assessed in 169 of 178 (95\%) patients. Eleven of these 169 CP patients (6\%) presented without $\mathrm{HI}$ at the time of diagnosis, 49 (29\%) were initially diagnosed with HI of anterior hypothalamic structures and 109 (64\%) were primarily diagnosed with preoperative $\mathrm{HI}$ of $\mathrm{a}+\mathrm{p}$ hypothalamic areas. We analyzed survival rates in all patients. Furthermore, BMI SDS in these 109 patients with presurgical, $\mathrm{a}+\mathrm{pHI}$ was analyzed at the time of diagnosis, at 1 and 3 years after CP diagnosis and at last follow-up visit. QoL could be analyzed by the Pediatric Quality of Life (PEDQOL) questionnaire at diagnosis in 55 of these $109 \mathrm{CP}$ patients (50\%) and during follow-up in 48 of 109 patients at standardized time points. Low patient number (55 of 109) is due to the following limitations: (1) missing data on QoL assessment at the time point 3 years after CP diagnosis in 30 patients, (2) incomplete QoL assessment (e.g. parental assessment was not completed) in 13 CP patients and (3) missing data on QoL in 11 patients.

\section{Clinical parameters}

Auxiological and clinical parameters were collected in all patients based on the KRANIOPHARYNGEOM 2007 trial protocol. Body height (SDS) (15) and body weight were obtained at diagnosis and prospectively at 3-month intervals after CP diagnosis. BMI (w/ $\mathrm{h}^{2} ; \mathrm{w}=$ weight/ kilogram, $\mathrm{h}=$ height/meter) was calculated and depicted as SDS according to the references of Rolland-Cachera et al. (16) for each subject at CP diagnosis and at standardized time points ( 1 and 3 years after CP diagnosis and at the last follow-up visit).

\section{Neuroimaging}

Cranial MRIs were performed according to the KRANIOPHARYNGEOM 2007 protocol $(17,18,19)$ at the time of CP diagnosis and prospectively at 3-month intervals during follow-up. Neuroradiological assessment of CP location, degree of surgical resection, preoperative $\mathrm{HI}$ and surgical HL was performed on pre- and postoperative axial, coronar and sagittal MRIs by a reference neuroradiologist (M W-M) blinded for clinical and surgical information. CP location was categorized according to the degree of HI: no HI detectable on presurgical MRIs; HI of anterior hypothalamic structures not involving mammillary bodies and hypothalamic structures dorsal of mammillary bodies; and HI of both $\mathrm{a}+\mathrm{p}$ hypothalamic areas, that is, involving anterior hypothalamic structures, mammillary bodies and hypothalamic areas dorsal of mammillary bodies $(17,18)$. Surgical HLs were graded based on postsurgical MRIs according to the same criteria in three categories: no HL: no HL detectable on postsurgical MRIs, anterior HL: HL of anterior hypothalamic structures not involving mammillary bodies, and $\mathrm{a}+\mathrm{pHL}$ : HL involving anterior hypothalamic structures, mammillary bodies and hypothalamic areas dorsal of mammillary bodies (Fig. 1).

\section{Treatment}

Neurosurgical treatment data were analyzed with regard to surgical approach, degree of surgical resection, and center size of neurosurgical institutions based on patient load
This work is licensed under a Creative Commons Attribution-NonCommercial-NoDerivatives 4.0 Internationab License.ifica.com at 04/26/2023 10:15:41AM 

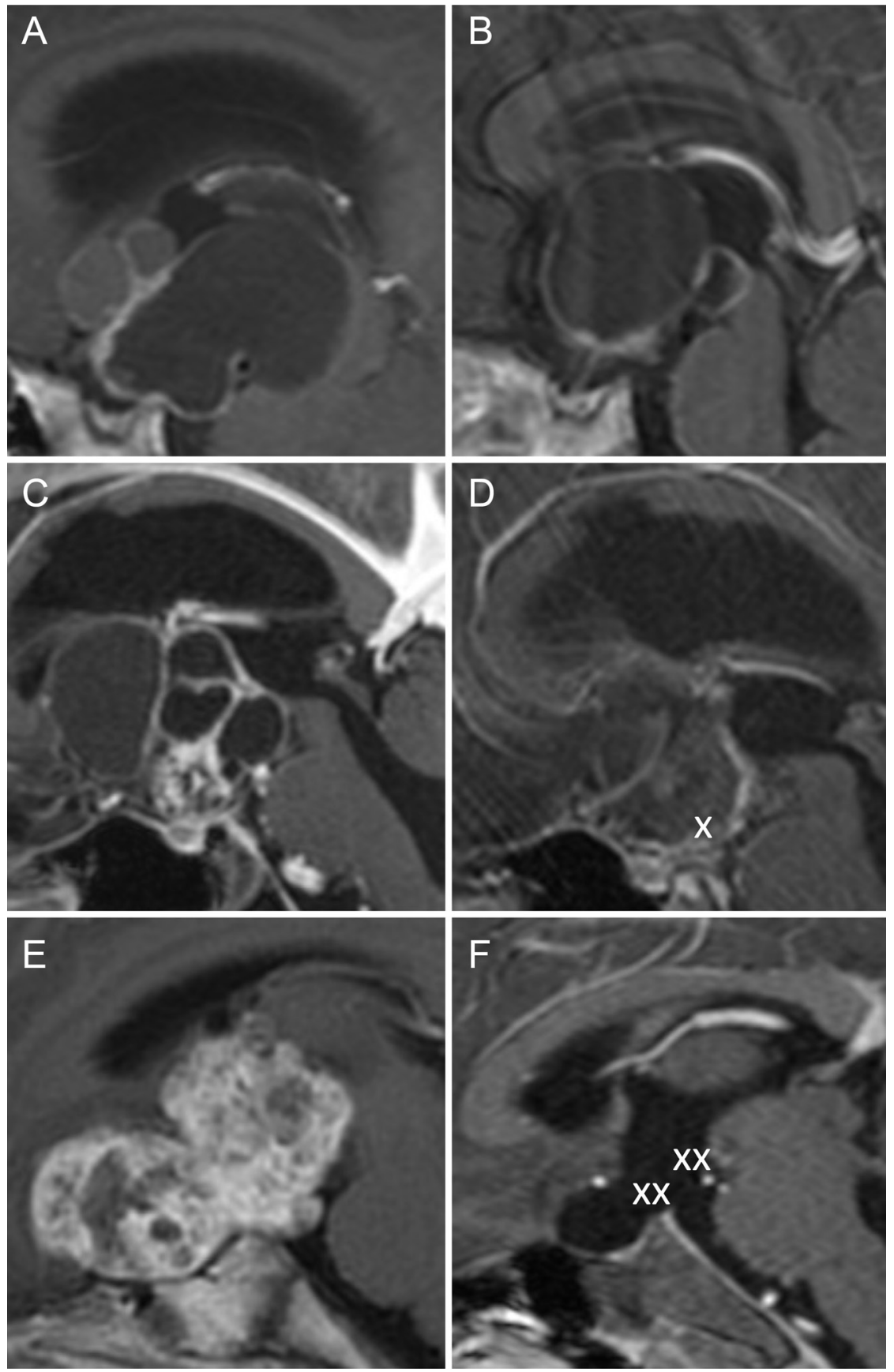

\section{Figure 1}

Presurgical (A, C and E) and postsurgical (B, D and F) MRIs of three childhood-onset

craniopharyngioma (CP) patients recruited in KRANIOPHARYNGEOM 2007 with initial preoperative anterior and posterior $(a+p) \mathrm{HI}$ graded as previously described $(17,18)$. In case (A), no hypothalamic lesions $(\mathrm{HL})$ were detectable on postsurgical MRI after cystic drainage via an inserted catheter (B). In case (C), HL of the anterior hypothalamus (marked with $X$ ) were detectable on postsurgical MRI (D). In case (E), HL of the $a+p$ hypothalamus (marked with XX) were detectable on postsurgical MRI (F).

during 7 years of CP recruitment in KRANIOPHARYNGEOM 2007 (small-sized centers: one patient; middle-sized centers: 2-5 patients; large-sized centers: $>5$ patients per 7 years recruitment period in KRANIOPHARYNGEOM 2007). Radiooncological treatment data were analyzed for radiation technique, age at initiation and radiation dose. In KRANIOPHARYNGEOM 2007, the decision on time point of irradiation (immediate irradiation vs irradiation at the time point of progression of residual tumor) was randomized for a small subgroup of patients
( $n=24)$ fulfilling the following inclusion criteria for the randomized trial: (a) 5 years or older at diagnosis and (b) reference-confirmed incomplete resection. In all the other patients recruited in KRANIOPHARYNGEOM 2007, the decision on radiotherapy was made by the local treating teams at participating hospitals according to the study recommendation to perform irradiation after incomplete resection.

Endocrine status was assessed with regard to hormonal substitution of deficient hypothalamic-pituitary axes. 


\section{QoL questionnaires}

In $\mathrm{CP}$ patients diagnosed at an age $\geq 5$ years, the PEDQOL (20) questionnaire was used to analyze QoL at standardized time points ( 1 and 3 years after $\mathrm{CP}$ diagnosis). Additionally, parental assessment of patient QoL was obtained by PEDQOL in patients younger than 18 years at study. The PEDQOL questionnaire is defining health-related QoL within seven domains (autonomy, emotional functionality, body image, cognition, physical function, social functionality in family and social functionality among friends). A high score is equivalent to more negative self or parental QoL assessment (20).

The German daily life ability scale Fertigkeitenskala Münster-Heidelberg (FMH) was used to analyze the functional capacity as a measure of QoL at the standardized time points 3 months, 1 and 3 years after CP diagnosis and at last visit. FMH assesses the capacity for routine actions in daily life with 56 items. It was normalized with 971 persons (45\% female), aged between 0 and 102 years, resulting in age-dependent percentiles (21). The average time for answering the FMH questionnaire is $4.5 \mathrm{~min}$ in first-time users (22).

\section{Statistical methods}

Statistical analyses were performed using SAS 9.4 (SAS Institute). Mann-Whitney $U$ test or Kruskal-Wallis test was used for comparison of continuous variables between two or more independent groups and Wilcoxon signedrank test or Friedmann test was used for comparison of two or more related groups for continuous variables. Fisher test was used for comparison of different groups for categorical variables. PFS and OS rates were estimated by Kaplan-Meier analyses and groups were compared using the log-rank test. Events for estimation of PFS were defined as neuroradiologically confirmed $>20 \%$ progression of residual tumor, reference-confirmed tumor recurrence after reference-confirmed complete surgical resection and death. The local significance level is set to 0.05 , that is, $P$ values of $\leq 0.05$ were considered statistically noticeable. No adjustment for multiple testing was applied. Therefore, inferential statistics are intended to be exploratory (hypotheses generating), not confirmatory, and are interpreted accordingly.

\section{Results}

One-hundred seventy-eight (94 females/84 males) patients diagnosed with CP (median age at CP diagnosis: 9.3 years, range: $1.3-17.9$ years) were recruited between 2007 and 2014 in our multinational, prospective KRANIOPHARYNGEOM 2007 trial (NCT00258453) (14). The histological diagnosis of adamantinomatous CP was confirmed by neuropathological reference assessment in all cases. Neurosurgical interventions were performed at 63 German, Austrian or Swiss neurosurgical institutions. Case distribution with regard to $\mathrm{HI}$ and $\mathrm{HL}$ over neurosurgical centers of different center size categorized according to patient load over 7-years recruitment (34 small-sized, 21 middle-sized and 8 large-sized neurosurgical centers) is depicted in Fig. 2. The occurrence of surgical posterior HL was similarly distributed with regard to center size (no posterior HL: small-sized centers 62\%, middle-sized centers 68\%, large-sized centers 67\%; posterior HL: smallsized centers 38\%, middle-sized centers 32\%, large-sized centers 33\%).

\begin{tabular}{|c|c|c|c|c|c|c|c|c|c|c|c|}
\hline & & \multicolumn{10}{|c|}{ Surgical hypothalamic lesions (HL) post OP } \\
\hline & & \multicolumn{3}{|c|}{ No HL } & \multicolumn{3}{|c|}{ Anterior HL } & \multicolumn{3}{|c|}{$\begin{array}{c}\text { Anterior }+ \\
\text { posterior HL }\end{array}$} & \multirow[t]{2}{*}{ Tota } \\
\hline \multicolumn{2}{|c|}{ Neurosurgical center size } & $\mathrm{S}$ & M & $\mathrm{L}$ & $\mathrm{S}$ & M & $\mathrm{L}$ & $\mathrm{S}$ & M & $\mathrm{L}$ & \\
\hline \multirow{6}{*}{$\begin{array}{c}\text { Hypothalamic } \\
\text { involvement } \\
\text { (HI) pre OP }\end{array}$} & \multirow{2}{*}{ No HI } & 3 & 3 & 5 & / & / & / & / & / & / & \multirow{2}{*}{11} \\
\hline & & \multicolumn{3}{|c|}{11} & \multicolumn{3}{|c|}{1} & \multicolumn{3}{|c|}{1} & \\
\hline & \multirow{2}{*}{$\begin{array}{c}\text { Anterior } \\
\text { HI }\end{array}$} & 2 & 10 & 5 & 5 & 15 & 12 & / & / & / & \multirow{2}{*}{49} \\
\hline & & \multicolumn{3}{|c|}{17} & \multicolumn{3}{|c|}{32} & \multicolumn{3}{|c|}{ / } & \\
\hline & \multirow{2}{*}{$\begin{array}{c}\text { Anterior }+ \\
\text { posterior } \\
\text { HI }\end{array}$} & 3 & 9 & 11 & 8 & 10 & 11 & 13 & 22 & 22 & \multirow{2}{*}{109} \\
\hline & & \multicolumn{3}{|c|}{23} & \multicolumn{3}{|c|}{29} & \multicolumn{3}{|c|}{57} & \\
\hline \multicolumn{2}{|c|}{ Total } & \multicolumn{3}{|c|}{51} & \multicolumn{3}{|c|}{61} & \multicolumn{3}{|c|}{57} & 169 \\
\hline
\end{tabular}

\section{Figure 2}

Distribution of 169 childhood-onset craniopharyngioma (CP) patients recruited in KRANIOPHARYNGEOM 2007 and neurosurgically treated at 63 neurosurgical institutions with different patient load per 7 years recruitment period in KRANIOPHARYNGEOM 2007. S, small-sized centers $(n=34)$ : one CP patient per 7 years; M, middle-sized centers $(n=21): 2-5 \mathrm{CP}$ patients per 7 years; and L, large-sized centers $(n=8)$ : $>5$ CP patients per 7 years recruitment period. Different degrees of primary presurgical involvement of anterior or anterior plus posterior hypothalamic areas are shown in table lines. Different degrees of surgical hypothalamic lesions $(\mathrm{HL})$ graded as previously described are shown in table columns $(17,18)$.

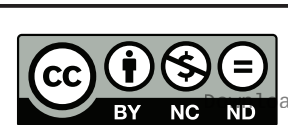

This work is licensed under a Creative Commons Attribution-NonCommercial-NoDerivatives 4.0 Internationab bicense.ifica.com at 04/26/2023 10:15:41AM 
In 169 of 178 recruited patients (95\%), the initial degree of HI and surgical HL could be reference assessed. Eleven of these 169 CP patients (7\%) presented without HI at the time of diagnosis, 49 (29\%) were initially diagnosed with HI of anterior hypothalamic structures and 109 (64\%) were primarily diagnosed with preoperative HI of $\mathrm{a}+\mathrm{p}$ hypothalamic areas (Fig. 2). These $109 \mathrm{CP}$ patients diagnosed with preoperative involvement of $\mathrm{a}+\mathrm{p}$ hypothalamic areas were included in our analysis of survival and weight development during follow-up. In 55 of these $109 \mathrm{CP}$ patients (50\%), PEDQOL were available for analysis of QoL. Functional capacity was assessed in all $109 \mathrm{CP}$ patients during follow-up. Surgical HL were reference-confirmed in 86 of 109 (79\%) CP patients (Table 1).

Data on the degree of surgical resection performed at 63 German, Austrian or Swiss neurosurgical centers were missing in 12 of 109 patients (11\%). Complete resection could be achieved in 77 of 97 patients (80\%) and incomplete resections in 20 of 97 patients (21\%). After complete surgical resection, CP patients showed a higher PFS $(P=0.02)$ when compared with PFS of patients after incomplete resection (Fig. 3A). The degree of surgical resection differed noticeably with regard to surgical HL $(P<0.0001)$. As expected per inclusion criteria, complete surgical resections always resulted in a+pHL (20/20). Incomplete resections were performed more frequently in patients without (79\%) or anterior HL $(97 \%)$ than in patients with $\mathrm{a}+\mathrm{pHL}(54 \%)$. OS rates (1.0 in all subgroups with different degree of HL) were similar, that is, no events were observed during follow-up. PFS rates were similar with regard to degree of HL (Fig. 3B). However, a trend toward higher PFS was observed in the $a+p H L$ cohort, when compared with the subgroups presenting postoperatively without or anterior HL. When adjusted for irradiation by analyzing the subgroup of nonirradiated patients, the PFS rate was noticeably higher in non-irradiated patients with $\mathrm{a}+\mathrm{pHL}(P=0.006)$ (Fig. 3C). Furthermore, the pairwise comparison of the subgroups $\mathrm{a}+\mathrm{pHL}$ and anterior HL shows a statistically noticeable difference concerning PFS $(P=0.03)$.

Baseline BMI SDS was similar in all HL subgroups at the time of diagnosis. Significant increases in BMI occurred in all HL subgroups during follow-up (median follow-up interval at last visit: 6.1 years, range: 3.01-10.21 years). However, CP with $\mathrm{a}+\mathrm{pHL}$ presented with higher BMI at

Table 1 Characteristics in 109 childhood-onset craniopharyngioma (CP) patients, recruited with primary presurgical involvement of anterior + posterior hypothalamus in KRANIOPHARYNGEOM 2007, with regard to surgical hypothalamic lesions (HL), graded as previously described $(17,18)$.

\begin{tabular}{l}
\hline \\
\hline Patients, $n$ (\%) \\
Gender (female/male) \\
Age at diagnosis (years) \\
Age at study (years) \\
Follow-up interval (years) \\
Tumor size (cm ${ }^{2}$ ) \\
Degree of resection, $n$ (\%) \\
Incomplete resection \\
Complete resection \\
n.a. \\
Surgical approach, $n$ (\%) \\
Transcranial approach \\
Transsphenoidal approach \\
Stereotactic cyst drainage \\
Open cyst drainage \\
n.a. \\
Irradiation (\%) \\
No irradiation \\
Age at irradiation (years) \\
Interval after dgx \\
Gamma knife treatment \\
Photon irradiation \\
Proton beam therapy \\
n.a.
\end{tabular}

\begin{tabular}{c}
\hline Total cohort \\
\hline $109(100)$ \\
$52 / 57$ \\
$9.6(1.3-17.9)$ \\
$16.4(4.6-28.0)$ \\
$6.1(3.0-10.2)$ \\
$4.0(0.3-34.6)$
\end{tabular}

$77(71)$
$20(18)$
$12(11)$

$62(57)$

$8(7)$

2 (2)

$3(3)$

34 (31)

$47(48)$

52 (53)

$10.7(2.5-18.7)$

0.9 (0.3-5.3)

1 (1)

$23(23)$

$23(23)$

$10(9)$

\begin{tabular}{c}
\hline No HL \\
\hline $23(21)$ \\
$12 / 11$ \\
$9.1(1.3-16.6)$ \\
$16.3(6.2-23.1)$ \\
$6.0(3.0-10.2)$ \\
$5.2(1.3-18.1)$
\end{tabular}

$$
18 \text { (78) }
$$$$
5 \text { (22) }
$$$$
8 \text { (34) }
$$$$
2(9)
$$$$
2 \text { (9) }
$$$$
2 \text { (9) }
$$$$
9 \text { (39) }
$$$$
16(73)
$$$$
6(27)
$$$$
9.6(4.0-18.7)
$$$$
0.6(0.3-4.1)
$$$$
\text { I }
$$$$
12(55)
$$

4 (18)

1 (4)

\begin{tabular}{c}
\hline Anterior HL \\
\hline $29(27)$ \\
$11 / 18$ \\
$10.1(1.6-17.9)$ \\
$16.8(5.1-28.0)$ \\
$6.4(3.0-10.2)$ \\
$3.7(0.3-32.1)$ \\
$28(97)$ \\
$/$ \\
$1(3)$ \\
$16(55)$ \\
$5(17)$ \\
$/$ \\
$1(3)$ \\
$7(24)$ \\
$15(56)$ \\
$12(44)$ \\
$12.7(2.5-18.7)$ \\
$0.9(0.4-5.3)$ \\
$/$ \\
$5(19)$ \\
$10(37)$ \\
$2(7)$ \\
\end{tabular}

\begin{tabular}{c}
\hline Anterior + posterior HL \\
\hline $57(52)$ \\
$29 / 28$ \\
$9.7(1.4-17.6)$ \\
$16.1(4.6-23.8)$ \\
$6.1(3.1-10.2)$ \\
$4.1(0.5-34.6)$ \\
$31(54)$ \\
$20(35)$ \\
$6(11)$ \\
$38(67)$ \\
$1(2)$ \\
$/$ \\
$/$ \\
$18(31)$ \\
$16(32)$ \\
$34(68)$ \\
$10.4(7.1-16.5)$ \\
$1.2(0.3-4.6)$ \\
$1(2)$ \\
$6(12)$ \\
$9(18)$ \\
$7(12)$
\end{tabular}

\begin{tabular}{c}
\hline \multicolumn{1}{c}{$\boldsymbol{P}$} \\
\hline n.s. \\
n.s. \\
n.s. \\
n.s. \\
n.s. \\
$<0.0001$
\end{tabular}

$<0.001$

0.004

n.s.

n.s.

0.05

In case of categorical variables, the $P$ value is calculated based on the sample with non-missing information.

https://ec.bioscientifica.com https://doi.org/10.1530/EC-19-0074 (c) 2019 The authors Published by Bioscientifica Ltd

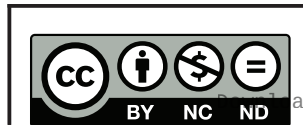

This work is licensed under a Creative Commons Attribution-NonCommercial-NoDerivatives 4.0 Internationab bicense.ifica . com at 04/26/2023 10:15:41AM 

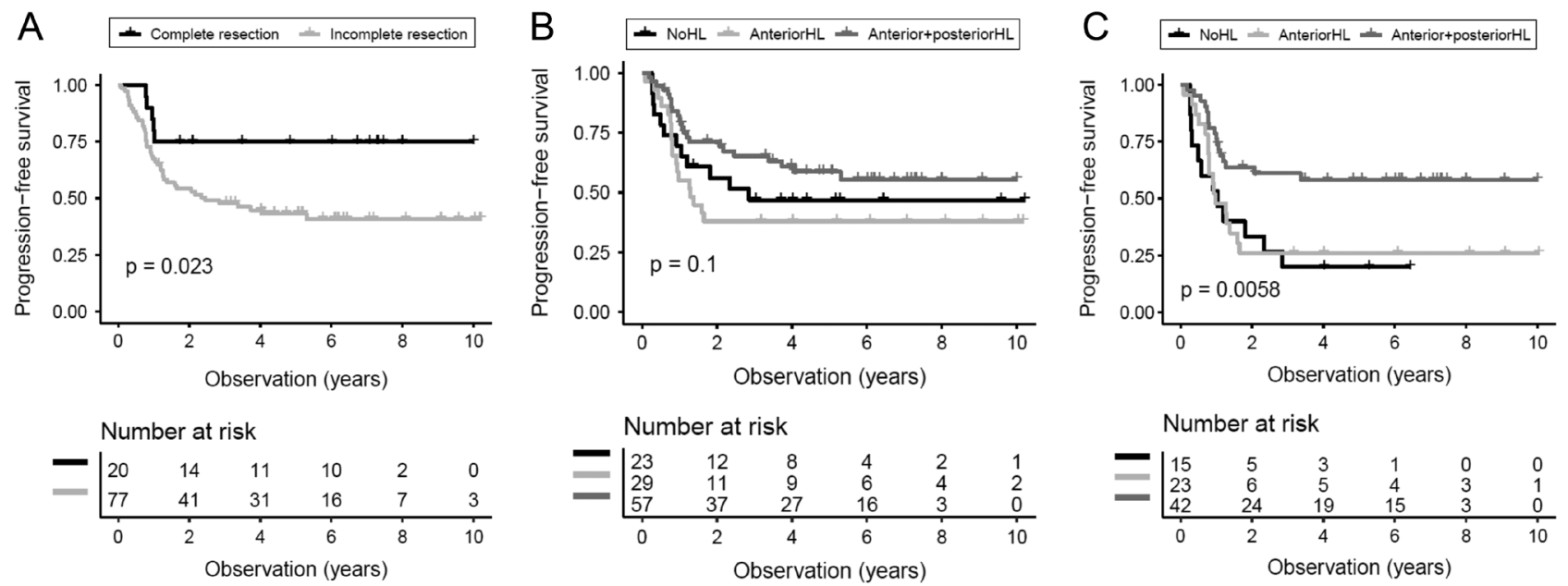

\section{Figure 3}

Kaplan-Meier analyses of progression-free survival (PFS) rates in childhood-onset craniopharyngioma (CP) patients, recruited with primary involvement of anterior and posterior $(a+p)$ hypothalamus in KRANIOPHARYNGEOM 2007, with regard to degree of surgical resection (A; $n=97$ ), surgical hypothalamic lesions $(\mathrm{HL})$ graded as previously described $(17,18)(\mathrm{B} ; n=109)$ : No $\mathrm{HL} ; \mathrm{HL}$ of the anterior hypothalamus not involving mammillary bodies and hypothalamic areas dorsal of mammillary bodies; and $\mathrm{HL}$ of $\mathrm{a}+\mathrm{p}$ hypothalamic areas, i.e. involving mammillary bodies and areas dorsal of mammillary bodies. (C) Depicts PFS with regards to hypothalamic lesions in non-irradiated CP patients with a $+\mathrm{pHL}(n=80)$.

the time points 1 year after diagnosis (median BMI: +5.21 $\mathrm{SD}$, range: -0.32 to $13.09 \mathrm{SD}$ ) and at last visit (median BMI: +5.74 SD, range: -0.82 to 14.65 SD), when compared to patients without HL (median BMI at 1 year follow-up: +1.72 SD, range: $1.54-8.09$ SD, $P=0.001$; at last visit: +2.33 SD, range: -1.77 to $10.98 \mathrm{SD}, P<0.001)$ and compared to patients with anterior $\mathrm{HL}$ (median BMI at 1-year follow-up: $+2.46 \mathrm{SD}$, range: -1.86 to $10.37 \mathrm{SD}, P=0.002$; at last visit: $+2.87 \mathrm{SD}$, range: -0.81 to $11.11 \mathrm{SD}, P=0.001)$. The development of severe obesity in patients with $\mathrm{a}+\mathrm{p}$ HL was due to significant weight increase during the first year after diagnosis $(P<0.001)$. Further significant increases of BMI SDS were not detectable after the first postsurgical year in any of the subgroups with different degree of HL (Fig. 4).

QoL in CP patients was parental and self-assessed by PEDQOL questionnaire during follow-up. At the time point 1 year after CP diagnosis, differences for PEDQOL domains did not reach statistical significance with regard to HL neither for self nor for parental assessment of QoL (Fig. 5A and C). Self-assessed QoL in patients with a $+\mathrm{pHL}$ significantly decreased between 1 and 3 years after surgery for the PEDQOL domains social functionality friends $(P=0.050)$ and family $(P=0.016)$. Decreased QoL was observed during further follow-up in CP with a + pHL when compared with CP patients without HL. At the time point 3 years after diagnosis, patients without HL scored better for the PEDQOL domain social functionality (family) in self and parental assessment $(P=0.014, P=0.002)$, whereas better scores for the PEDQOL domains physical function $(P=0.047)$ and emotional stability $(P=0.040)$ were observed for patients without HL only in parental assessment, when compared to CP patients with $\mathrm{a}+\mathrm{pHL}$ (Fig. 5B and D). At the time point 1 year after surgery, parents estimated QoL worse with regard to PEDQOL domains emotional stability, body image and physical functionality than patients in all respective HL subgroups. At the time point 3 years after surgery, parental rating for the PEDQOL domains physical function $(P=0.026)$ and social functionality with friends $(P=0.028)$ was worse for the subgroup of patients with $\mathrm{a}+\mathrm{pHL}$ (Fig. 5). Differences in terms of functional capacity did not reach statistical significance during follow-up with regard to HL (Fig. 6).

In ten patients, it was not clarified if irradiation was performed. Forty-six of 99 patients (47\%) were irradiated with conventional fractionated target volume doses of 50.4-54.0 Gy (mean dose: 53.3 Gy). One case was treated by Gamma Knife with volume doses of $24 \mathrm{~Gy}$. Twentythree of 46 irradiated CP patients (50\%) were treated by photon irradiation; 23 of 46 patients (50\%) received proton beam therapy. The highest rate of irradiation was observed in the cohort without HL (70\%) when compared to the subgroup with anterior HL (52\%) and patients with $\mathrm{a}+$ pHL (28\%) $(P=0.004)$ (Table 1).

Noticeable differences in terms of endocrine deficiencies were not observed between the CP patient subgroups of irradiated and non-irradiated patients with different degree of $\mathrm{HL}$ at last visit except for central
This work is licensed under a Creative Commons Attribution-NonCommercial-NoDerivatives 4.0 enternationab bicense.ifica.com at 04/26/2023 10:15:41AM 


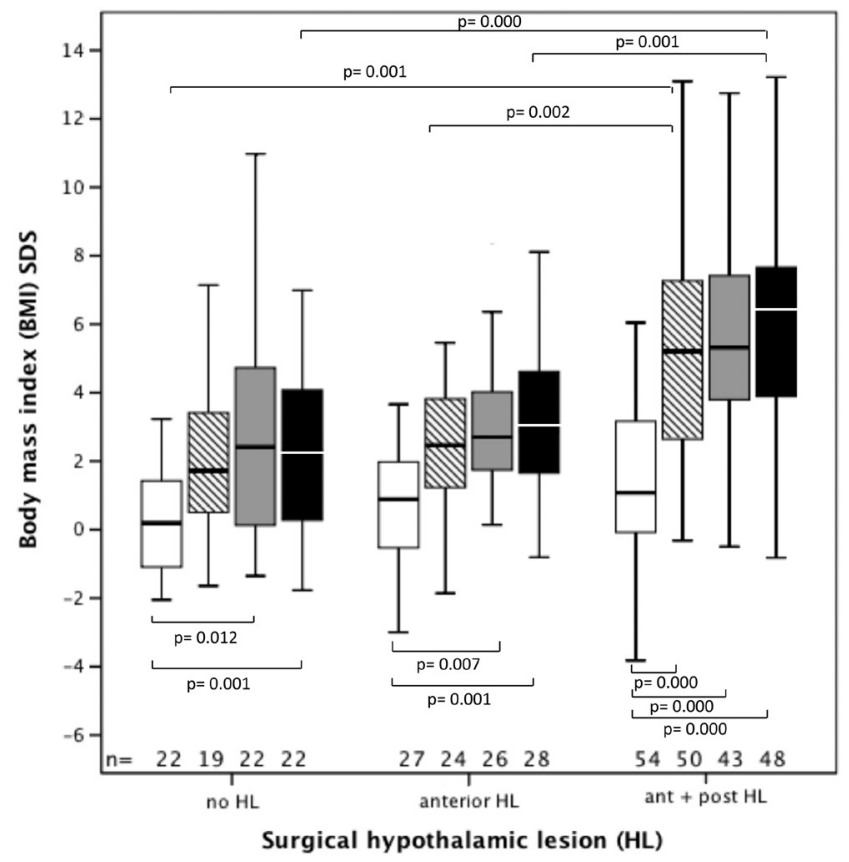

Figure 4

Weight development in 109 childhood-onset craniopharyngioma (CP) patients, recruited with primary involvement of anterior and posterior $(a+p)$ hypothalamus in KRANIOPHARYNGEOM 2007, with regard to surgical hypothalamic lesions $(\mathrm{HL})$ graded as previously described $(17,18)$ : $\mathrm{No} \mathrm{HL} ; \mathrm{HL}$ of the anterior hypothalamus not involving mammillary bodies and hypothalamic areas dorsal of mammillary bodies; and $\mathrm{HL}$ of $\mathrm{a}+\mathrm{p}$ hypothalamic areas, i.e. involving mammillary bodies and areas dorsal of mammillary bodies. BMI SDS (16) is shown at time of diagnosis and at three intervals after diagnosis (one and 3 years after diagnosis, last visit). White boxes: BMI SDS at diagnosis; hatched boxes: BMI SDS at one year follow-up; gray boxes: BMI SDS at 3 years follow-up, and black boxes: BMI SDS at last visit. The horizontal line in the middle of the box depicts the median. The top and bottom edges of the box respectively mark the 25th and 75 th percentiles. Whiskers indicate the range of values that fall within 1.5 box-lengths.

diabetes insipidus. Diabetes insipidus was observed more frequently in patients with HL, with the difference being statistically noticeable in the subgroup of irradiated patients $(P=0.030)$. However, the analysis of association of $\mathrm{HL}$ and endocrine deficiencies is limited due to small sample size and incomplete data (Table 2).

\section{Discussion}

Hypothalamic syndrome and the development of morbid obesity are major sequelae with negative impact on prognosis after CP (23). However, there is still considerable debate $(24,25,26,27)$, whether initial presurgical HI or treatment-related surgical HL or both determine prognosis and QoL after CP. De Vile et al. (28) first reported on the association between gross total resection and adverse long-term outcome in CP patients. The Necker group at Paris, France $(29,30)$ developed an algorithm for neurosurgical treatment of $\mathrm{CP}$ patients, recommending a risk-adapted hypothalamus-sparing surgical strategy based on a novel MRI-based grading system of presurgical HI (29). The authors (30) could show that CP patients surgically treated according to their hypothalamus-sparing approach presented with similar relapse and progression rates and a lower rate of morbid obesity when compared with their historical cohort of CP patients treated by grosstotal resection (28 vs $54 \%$, respectively) (30). This was the first report proving the efficacy of a hypothalamus-sparing surgical (HSS) approach by comparing CP patient cohorts treated by the same experienced neurosurgical team at a single center, and thus minimizing potential bias of surgical experience on outcome analyses. But validation of this observation in a prospective multicenter setting is still missing. Notably, this HSS strategy increased the rate of 'normal' BMI from 17 to 38\%. However, the percentage of clinically relevant weight gain remained $62 \%$ with nearly $50 \%$ of all CP patients developing morbid obesity during follow-up. Furthermore, the mean number of surgical interventions per patient, used as a surrogate for the local recurrence rate, was not noticeably different between the two groups (1.45 in the extensive resection surgery (ERS) group and 1.52 in the HSS group). However, follow-up was markedly shorter in the HSS group (mean, 33 months) when compared with the historical group treated by gross-total resection (mean, 103 months). We previously analyzed effects of risk-adapted treatment strategies on outcome after CP based on pre and postsurgical grading of HI and HL in MRI $(17,18,31,32)$. Tumor location and hypothalamic damage with regard to mammillary bodies is essential for our grading of anterior or $\mathrm{a}+\mathrm{pHI}$ and HL. Based on multivariate risk analysis including initial preoperative $\mathrm{HI}$ and surgical HL, presurgical HI was reported to be the major independent risk factor for the development of morbid obesity in CP regardless of chosen surgical strategy and degree of surgical HL (17).

In previous studies on our KRANIOPHARYNGEOM 2007 cohort, we reported on short-term QoL with regard to growth hormone substitution (32) and the concordance between surgical and neuroradiological assessment of $\mathrm{HI}$ and HL (31). In the current study, we analyzed CP patients recruited in KRANIOPHARYNGEOM 2007 with presurgical $\mathrm{a}+\mathrm{pHI}$, that is, patients at high risk for hypothalamic syndrome, in terms of outcome with regard to surgical HL. Notably, radical surgical approaches in these patients resulting in $\mathrm{a}+\mathrm{pHL}$ were associated with lower relapse/progression rates and highest PFS.

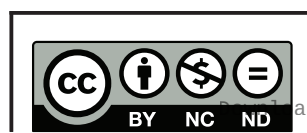

This work is licensed under a Creative Commons Attribution-NonCommercial-NoDerivatives 4.0 Internationab sicense.ifica.com at 04/26/2023 10:15:41AM 

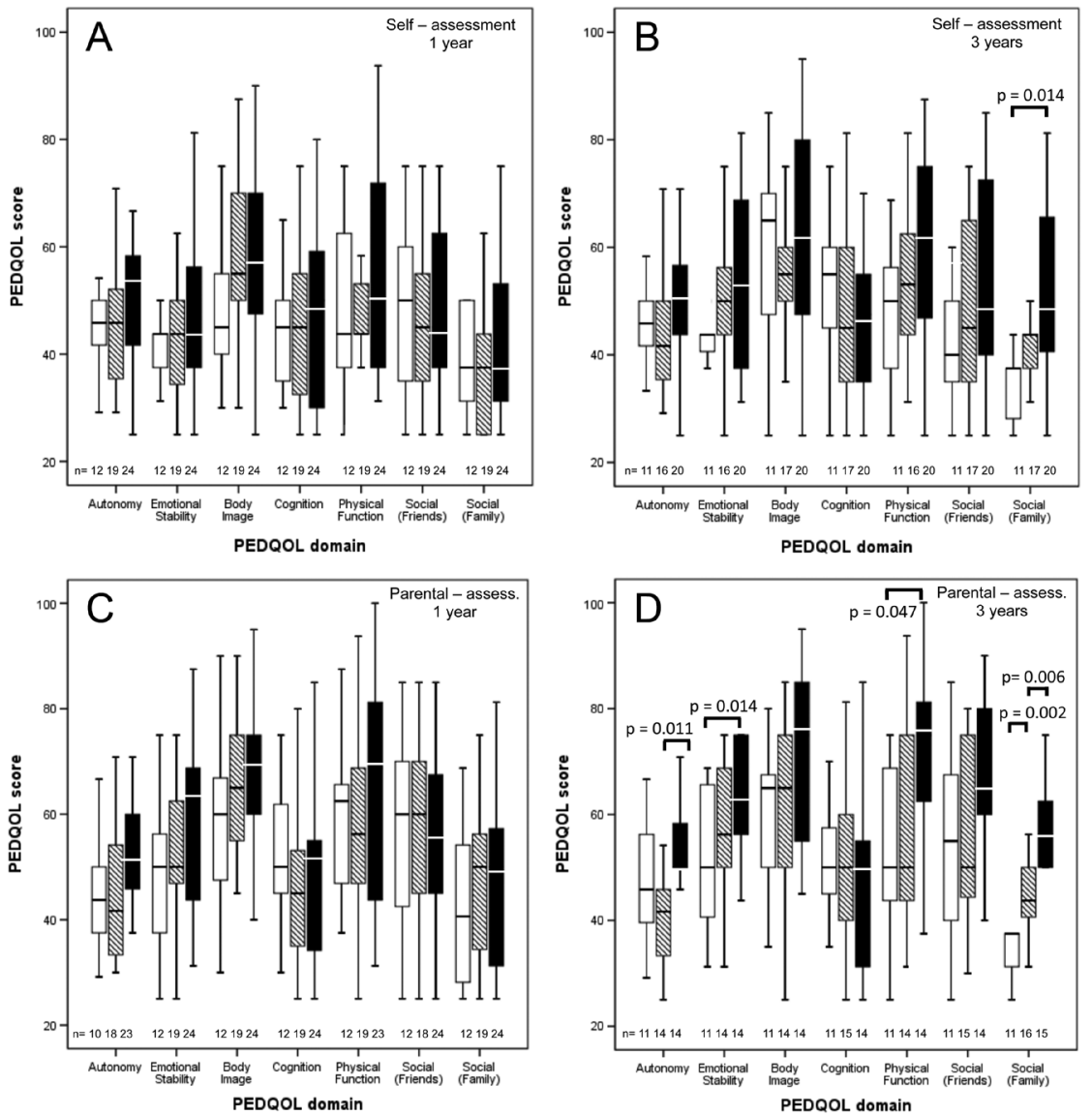

\section{Figure 5}

Self-assessment (A and B) and parental assessment ( $C$ and $D$ ) of quality of life by Pediatric Quality of Life Questionnaire (PEDQOL) in 55 childhood-onset craniopharyngioma (CP) patients, recruited with primary involvement of anterior and posterior hypothalamus in KRANIOPHARYNGEOM 2007, with regard to surgical hypothalamic lesions $(\mathrm{HL})$ graded as previously described $(17,18)$. White boxes: no $\mathrm{HL}$, hatched boxes: anterior $\mathrm{HL}$, and black boxes: anterior plus posterior HL. PEDQOL scores are shown as negative rating at the time points 1 year ( $A$ and $C$ ) and 3 years ( $B$ and $D$ ) after CP diagnosis. The horizontal line in the middle of the box depicts the median. The top and bottom edges of the box respectively mark the 25 th and 75 th percentiles. Whiskers indicate the range of values that fall within 1.5 box-lengths.
Furthermore, when adjusted for irradiation, a higher PFS was observed for non-irradiated patients with a $+\mathrm{pHL}$. These differences were smaller in a non-adjusted comparison of the total, irradiated and non-irradiated subgroups. Notably, patients without HL had the highest rates of radiation because they were frequently treated with an upfront strategy of conservative surgery and radiation therapy. While the patients were treated at manyinstitutions, it seems fairly clear that this was an intentional strategy. Accordingly, we recommend to include radiooncological treatment options in multidisciplinary strategies aiming at hypothalamus-sparing approaches $(7,13,30,33,34,35)$.

However, patients with surgical $\mathrm{a}+\mathrm{pHL}$ due to radical gross-total resection presented with significantly higher BMI SDS and decreased QoL scores at all time points during follow-up when compared with CP not suffering from surgical lesions extending to posterior hypothalamic structures. Notably, limited HL confined to anterior hypothalamic structures had similar, i.e. no clinically severe, adverse effect on weight development and QoL, when compared to patients without HL. The timing of decline in QoL scores (after 1 year from surgery) also merits emphasis, as this could guide parental counseling and supportive efforts by the healthcare system.

Functional capacity was not impaired with regard to HL. We speculate that impairments of functional capacity are most likely to occur during further long-term follow-up of patients with or without HL, which will be analyzed in future studies on this cohort.

The results of our study also provide novel insights into the course of disease. As previously reported $(36,37$, 38, 39), CP patients at risk for hypothalamic syndrome and severe obesity typically present with significant increase of weight during the first year after diagnosis/ surgery and BMI reaches a plateau of severe obesity without further increase during long-term follow-up, that is weight increase in the $\mathrm{a}+\mathrm{pHL}$ group occurred during the first year after surgery, but not afterward (7). Based on our observation, this typical pattern in course of disease is associated with specific clinical risk factors. Neither preoperative HI nor anterior surgical HL seems to predispose for significant early weight gain during the first year after CP diagnosis, but specific posterior HLs are observed to have a causative impact. Accordingly, the current recommendation of hypothalamus-sparing 


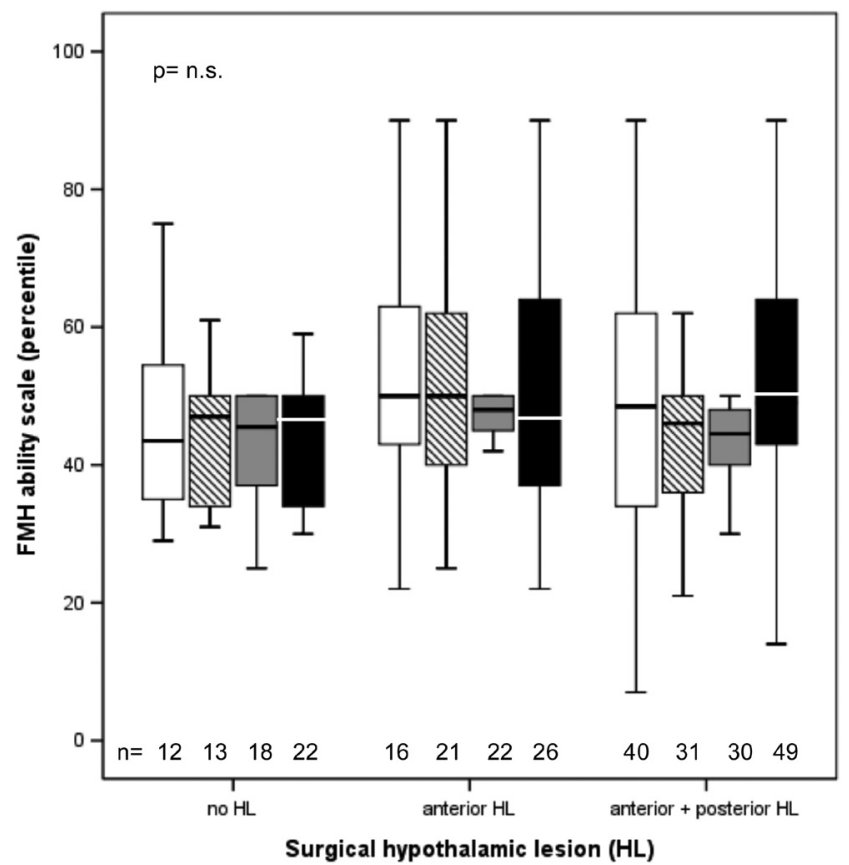

Figure 6

Functional capacity as quantified by German daily life ability scale Fertigkeitenskala Münster-Heidelberg (FMH) in 109 childhood-onset craniopharyngioma (CP) patients, recruited with primary involvement of anterior and posterior $(a+p)$ hypothalamus in KRANIOPHARYNGEOM 2007, with regard to surgical hypothalamic lesions (HL) graded as previously described $(17,18)$ : No HL; $\mathrm{HL}$ of the anterior hypothalamus not involving mammillary bodies and hypothalamic areas dorsal of mammillary bodies and $\mathrm{HL}$ of $\mathrm{a}+\mathrm{p}$ hypothalamic areas, i.e. involving mammillary bodies and areas dorsal of mammillary bodies. FMH scores are shown at time of diagnosis and at three intervals after diagnosis (one and 3 years after diagnosis, last visit). White boxes: $\mathrm{FMH}$ at diagnosis; hatched boxes: FMH at 1-year follow-up; gray boxes: FMH at 3-year follow-up and black boxes: FMH at last visit. The horizontal line in the middle of the box depicts the median. The top and bottom edges of the box respectively mark the 25 th and 75 th percentiles. Whiskers indicate the range of values that fall within 1.5 box-lengths.

surgery should be more specifically focused on a 'posterior hypothalamus-sparing' strategy.

In our study, the occurrence of surgical posterior $\mathrm{HL}$ was not related to surgical center size, as presurgical HI and surgical HL were evenly distributed over neurosurgical centers of different center size. This might indicate a current shift toward limited, HSS strategies when compared to earlier reports in the literature (33).

It is well known that HL can cause severe dysregulation of body composition and energy expenditure at several levels, resulting in hypothalamic syndrome characterized by fatigue, decreased sympathetic tone, decreased energy expenditure and physical activity, hyperphagia, decreased satiety, as well as severe obesity (38, 40, 41, 42, 43, 44, 45, 46, 47, 48). Hypothalamic nuclei with posterior location such as dorsomedial nucleus (DMN), dorsal hypothalamic area nucleus and ventromedial nucleus (VMN) are key regulators for thermoregulation and locomotion mediating leptininduced sympathetic activation of brown adipose tissue and energy expenditure (47). Studies in a rodent model for lesion-induced hypothalamic obesity showed that mainly lesions affecting these posterior hypothalamic nuclei were associated with the classical phenotype of hypothalamic obesity (49). Roth et al. (47) confirmed these observations in an imaging study on patients with different sellar masses, analyzing the location of HL and association with patient outcome.

Due to rareness of the disease, the cohort size of our study is limited. Nevertheless, we are reporting on the - to our knowledge - largest specific subgroup of CP patients initially presenting with severe $\mathrm{a}+\mathrm{pHI}$. As a limitation, our preoperative image grading system has not been validated yet, which is the aim of future studies. Furthermore, the MRIs depicted in Fig. 1 are not adequate to fully illustrate how neuroradiological reference assessment of HL was performed.

Whereas survival rates, BMI development and functional capacity could be assessed with a high grade of completeness during follow-up, QoL analysis was limited to a subgroup of $55 \mathrm{CP}$ patients, for whom complete data sets for self and parental-rated PEDQOL scores were

Table 2 Hypothalamic-pituitary endocrine deficiencies at last visit in childhood-onset craniopharyngioma patients (n), recruited with primary presurgical involvement of anterior + posterior hypothalamus in KRANIOPHARYNGEOM 2007, with regard to surgical hypothalamic lesions $(\mathrm{HL})$, graded as previously described $(17,18)$ and irradiation $(\mathrm{XRT})$.

\begin{tabular}{|c|c|c|c|c|c|c|c|c|c|c|}
\hline & \multicolumn{2}{|c|}{ Total cohort } & \multicolumn{2}{|c|}{ No HL } & \multicolumn{2}{|c|}{ Ant HL } & \multicolumn{2}{|c|}{ Ant + post HL } & \multicolumn{2}{|c|}{$\boldsymbol{P}$} \\
\hline & No XRT & XRT & No XRT & XRT & No XRT & XRT & No XRT & XRT & No XRT & XRT \\
\hline Diabetes insipidus centralis, $n$ & 43 & 35 & 3 & 8 & 11 & 13 & 29 & 14 & 0.068 & 0.030 \\
\hline Growth hormone deficiency, $n$ & 33 & 27 & 5 & 9 & 8 & 8 & 20 & 10 & 1.0 & 1.0 \\
\hline Hypothyroidism, $n$ & 41 & 39 & 5 & 12 & 8 & 13 & 28 & 14 & 0.645 & 0.701 \\
\hline Hypocortisolism, $n$ & 40 & 35 & 3 & 11 & 8 & 11 & 29 & 13 & 0.085 & 0.734 \\
\hline Hypogonadism, $n$ & 15 & 17 & 2 & 6 & 3 & 6 & 10 & 5 & 0.886 & 0.829 \\
\hline
\end{tabular}

The $P$ values refer to comparisons between the hypothalamic lesion subgroups within the context of whether or not the patient received XRT. ant, anterior; HL, hypothalmic surgical lesion; post, posterior.

https://ec.bioscientifica.com https://doi.org/10.1530/EC-19-0074 (c) 2019 The authors Published by Bioscientifica Ltd

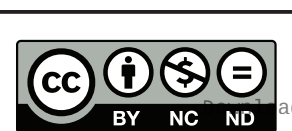

This work is licensed under a Creative Commons Attribution-NonCommercial-NoDerivatives 4.0 Internationab bicense.ifica . com at $04 / 26 / 2023$ 10:15:41AM 
available. Increasing patient numbers and prolonging follow-up for assessment of long-term outcome are goals of future studies.

In conclusion, our current study analyzes a large cohort of CP patients at special risk for hypothalamic obesity due to presurgical HI and shows that posterior hypothalamus-sparing strategies prevent QoL impairments and ameliorate the development of obesity in this subgroup. Effects of preoperative HI as apriori risk factor for adverse outcome can be modified by risk-adapted surgical strategies aiming at prevention of further posterior HL. Limited surgical HL confined to anterior hypothalamic structures result in minor adverse effects, whereas posterior HL are clinically relevant risk factors for the development of hypothalamic syndrome. Neither preoperative HI nor postoperative anterior HL is associated with early weight gain. As such, the goals of the surgical approach are critical and should aim specifically to avoid posterior hypothalamic damage. However, HSS strategies are also associated with higher risk for relapse and progression of residual tumor. Radiooncological therapy is effective in treatment and prevention of relapse/progression and therefore plays an important role in hypothalamus-sparing treatment strategies for $\mathrm{CP}$ (1). Standardization of preoperative and postoperative staging is recommended for multidisciplinary decision on risk-appropriate treatment strategy in childhoodonset CP (50).

\section{Declaration of interest}

The authors declare that there is no conflict of interest that could be perceived as prejudicing the impartiality of the research reported.

\section{Funding}

This study was funded by a grant (H L M; DKS2014.13) of The German Childhood Cancer Foundation, Bonn, Germany. The publication resulted from collaboration (A B) made possible through the Merck sponsored educational program 'ESPE Clinical Fellowship'.

\section{Author contribution statement}

A B researched the data and wrote the manuscript. S B conducted and supervised multicenter data collecting and reviewed/edited the manuscript. M W-M performed neuroradiological reference assessments, participated in data analyses and reviewed/edited the manuscript. G C performed PEDQOL data analyses on QoL, participated in data analyses and reviewed/edited the manuscript. M E advised statistical data analyses and reviewed/edited the manuscript. $\mathrm{H} L \mathrm{M}$ initiated and conducted the multicenter trials Hit-Endo KRANIOPHARYNGEOM 2000/2007, contributed to the analytical plan and discussion and reviewed/edited the manuscript.

\section{Ethical standards}

All procedures performed in our study were in accordance with the ethical standards of the institutional and/or national research committee and with the 1964 Helsinki Declaration and its later amendments or comparable ethical standards. The study was approved by the local standing committee on ethical practice (Würzburg University, Germany, 94/06) and written parental and/or patient consent was obtained in all cases.

\section{Acknowledgements}

The authors want to thank all participating colleagues for recruiting patients in KRANIOPHARYNGEOM 2000/2007, and the patients and their parents for participating in this study.

\section{References}

1 Muller HL, Merchant TE, Puget S \& Martinez-Barbera JP. New outlook on the diagnosis, treatment and follow-up of childhood-onset craniopharyngioma. Nature Reviews Endocrinology 201713 299-312. (https://doi.org/10.1038/nrendo.2016.217)

2 Muller HL. Craniopharyngioma. Endocrine Reviews 201435 513-543. (https://doi.org/10.1210/er.2013-1115)

3 Muller HL. Consequences of craniopharyngioma surgery in children. Journal of Clinical Endocrinology and Metabolism 201196 1981-1991. (https://doi.org/10.1210/jc.2011-0174)

4 Karavitaki N, Cudlip S, Adams CBT \& Wass JAH. Craniopharyngiomas. Endocrine Reviews 200627 371-397. (https:// doi.org/10.1210/er.2006-0002)

5 Martinez-Barbera JP. Molecular and cellular pathogenesis of adamantinomatous craniopharyngioma. Neuropathology and Applied Neurobiology 201541 721-732. (https://doi.org/10.1111/nan.12226)

6 Olsson DS, Andersson E, Bryngelsson IL, Nilsson AG \& Johannsson G. Excess mortality and morbidity in patients with craniopharyngioma, especially in patients with childhood onset: a population-based study in Sweden. Journal of Clinical Endocrinology and Metabolism 2015100 467-474. (https://doi.org/10.1210/jc.20143525)

7 Sterkenburg AS, Hoffmann A, Gebhardt U, Warmuth-Metz M, Daubenbuchel AM \& Muller HL. Survival, hypothalamic obesity, and neuropsychological/psychosocial status after childhood-onset craniopharyngioma: newly reported long-term outcomes. NeuroOncology 201517 1029-1038. (https://doi.org/10.1093/neuonc/ nov044)

8 Holmer H, Ekman B, Björk J, Nordstöm CH, Popovic V, Siversson A \& Erfurth EM. Hypothalamic involvement predicts cardiovascular risk in adults with childhood onset craniopharyngioma on long-term GH therapy. European Journal of Endocrinology 2009161 671-679. (https://doi.org/10.1530/EJE-09-0449)

9 Wijnen M, van den Heuvel-Eibrink MM, Janssen JAMJL, Catsman-Berrevoets CE, Michiels EMC, van Veelen-Vincent MC, Dallenga AHG, van den Berge JH, van Rij CM, van der Lely AJ, et al. Very long-term sequelae of craniopharyngioma. European Journal of Endocrinology 2017176 755-767. (https://doi.org/10.1530/EJE-170044)

10 Wijnen M, Olsson DS, van den Heuvel-Eibrink MM, Hammarstrand C, Janssen JAMJL, van der Lely AJ, Johannsson G \& Neggers SJCMM. The metabolic syndrome and its components in 178 patients treated for craniopharyngioma after 16 years of follow-up. European Journal of Endocrinology 2018178 11-22. (https:// doi.org/10.1530/EJE-17-0387)

11 Muller HL. Diagnostics, treatment, and follow-up in craniopharyngioma. Frontiers in Endocrinology 20112 70. (https://doi. org/10.3389/fendo.2011.00070) 
12 Muller HL. Paediatrics: surgical strategy and quality of life in craniopharyngioma. Nature Reviews Endocrinology 20139 447-449. (https://doi.org/10.1038/nrendo.2013.125)

13 Mortini P, Gagliardi F, Bailo M, Spina A, Parlangeli A, Falini A \& Losa M. Magnetic resonance imaging as predictor of functional outcome in craniopharyngiomas. Endocrine 201651 148-162. (https://doi.org/10.1007/s12020-015-0683-x)

14 Muller HL, Gebhardt U, Etavard-Gorris N, Korenke E, WarmuthMetz M, Kolb R, Sörensen N \& Calaminus G. Prognosis and sequela in patients with childhood craniopharyngioma - results of HIT-ENDO and update on KRANIOPHARYNGEOM 2000. Klinische Padiatrie 2004216 343-348. (https://doi.org/10.1055/s-2004-832339)

15 Prader A, Largo RH, Molinari L \& Issler C. Physical growth of Swiss children from birth to 20 years of age. First Zurich longitudinal study of growth and development. Helvetica Paediatrica Acta Supplementum 198952 1-125.

16 Rolland-Cachera MF, Cole TJ, Sempe M, Tichet J, Rossignol C \& Charraud A. Body mass index variations: centiles from birth to 87 years. European Journal of Clinical Nutrition 1991 45 13-21.

17 Muller HL, Gebhardt U, Teske C, Faldum A, Zwiener I, WarmuthMetz M, Pietsch T, Pohl F, Sörensen N \& Calaminus G. Post-operative hypothalamic lesions and obesity in childhood craniopharyngioma: results of the multinational prospective trial KRANIOPHARYNGEOM 2000 after 3-year follow-up. European Journal of Endocrinology 2011 165 17-24. (https://doi.org/10.1530/EJE-11-0158)

18 Muller HL, Gebhardt U, Faldum A, Warmuth-Metz M, Pietsch T, Pohl F, Calaminus G, Sörensen N \& KRANIOPHARYNGEOM 2000 Study Committee. Xanthogranuloma, Rathke's cyst, and childhood craniopharyngioma: results of prospective multinational studies of children and adolescents with rare sellar malformations. Journal of Clinical Endocrinology and Metabolism 201297 3935-3943. (https:// doi.org/10.1210/jc.2012-2069)

19 Warmuth-Metz M, Gnekow AK, Muller HL \& Solymosi L. Differential diagnosis of suprasellar tumors in children. Klinische Padiatrie 2004 216 323-330. (https://doi.org/10.1055/s-2004-832358)

20 Calaminus G, Weinspach S, Teske C \& Gobel U. Quality of life in children and adolescents with cancer. First results of an evaluation of 49 patients with the PEDQOL questionnaire. Klinische Padiatrie 2000 212 211-215. (https://doi.org/10.1055/s-2000-9679)

21 Wolff JE, Daumling E, Dirksen A, Dabrock A, Hartmann M \& Jurgens H. Munster Heidelberg abilities scale - a measuring instrument for global comparison of illness sequelae. Klinische Padiatrie 1996208 294-298. (https://doi. org/10.1055/s-2008-1046486)

22 Muller HL, Gebhardt U, Faldum A, Emser A, Etavard-Gorris N, Kolb R \& Sörensen N. Functional capacity and body mass index in patients with sellar masses - cross-sectional study on 403 patients diagnosed during childhood and adolescence. Child's Nervous System 200521 539-545. (https://doi.org/10.1007/s00381-005-1166-9)

23 Cohen M, Bartels U, Branson H, Kulkarni AV \& Hamilton J. Trends in treatment and outcomes of pediatric craniopharyngioma, 19752011. Neuro-Oncology 201315 767-774. (https://doi.org/10.1093/ neuonc/not026)

24 Sainte-Rose C, Puget S, Wray A, Zerah M, Grill J, Brauner R, Boddaert N \& Pierre-Kahn A. Craniopharyngioma: the pendulum of surgical management. Child's Nervous System 200521 691-695. (https://doi.org/10.1007/s00381-005-1209-2)

25 Hankinson TC, Palmeri NO, Williams SA, Torok MR, Serrano CA, Foreman NK, Handler MH \& Liu AK. Patterns of care for craniopharyngioma: survey of members of the American Association of Neurological Surgeons. Pediatric Neurosurgery 201349 131-136. (https://doi.org/10.1159/000357783)

26 Van Gompel JJ, Nippoldt TB, Higgins DM \& Meyer FB. Magnetic resonance imaging-graded hypothalamic compression in surgically treated adult craniopharyngiomas determining postoperative obesity.
Neurosurgical Focus 201028 E3. (https://doi.org/10.3171/2010.1.FO CUS09303)

27 Buchfelder M, Schlaffer SM, Lin F \& Kleindienst A. Surgery for craniopharyngioma. Pituitary 201316 18-25. (https://doi. org/10.1007/s11102-012-0414-8)

28 De Vile CJ, Grant DB, Kendall BE, Neville BG, Stanhope R, Watkins KE \& Hayward RD. Management of childhood craniopharyngioma: can the morbidity of radical surgery be predicted? Journal of Neurosurgery 199685 73-81. (https://doi. org/10.3171/jns.1996.85.1.0073)

29 Puget S, Garnett M, Wray A, Grill J, Habrand JL, Bodaert N, Zerah M, Bezerra M, Renier D, Pierre-Kahn A, et al. Pediatric craniopharyngiomas: classification and treatment according to the degree of hypothalamic involvement. Journal of Neurosurgery 2007 106 3-12. (https://doi.org/10.3171/ped.2007.106.1.3)

30 Elowe-Gruau E, Beltrand J, Brauner R, Pinto G, Samara-Boustani D, Thalassinos C, Busiah K, Laborde K, Boddaert N, Zerah M, et al. Childhood craniopharyngioma: hypothalamus-sparing surgery decreases the risk of obesity. Journal of Clinical Endocrinology and Metabolism 201398 2376-2382. (https://doi.org/10.1210/jc.20123928)

31 Muller HL, Reichel J, Boekhoff S, Warmuth-Metz M, Eveslage M, Peng J \& Flitsch J. Low concordance between surgical and radiological assessment of degree of resection and treatment-related hypothalamic damage: results of KRANIOPHARYNGEOM 2007. Pituitary 201821 371-378. (https://doi.org/10.1007/s11102-0180883-5)

32 Heinks K, Boekhoff S, Hoffmann A, Warmuth-Metz M, Eveslage M, Peng J, Calaminus G \& Müller HL. Quality of life and growth after childhood craniopharyngioma: results of the multinational trial KRANIOPHARYNGEOM 2007. Endocrine 201859 364-372. (https:// doi.org/10.1007/s12020-017-1489-9)

33 Hoffmann A, Warmth-Metz M, Gebhardt U, Pietsch T, Pohl F, Kortmann RD, Calaminus G \& Müller HL. Childhood craniopharyngioma - changes of treatment strategies in the trials KRANIOPHARYNGEOM 2000/2007. Klinische Padiatrie 2014226 161-168. (https://doi.org/10.1055/s-0034-1368785)

34 Flitsch J, Muller HL \& Burkhardt T. Surgical strategies in childhood craniopharyngioma. Frontiers in Endocrinology 20112 96. (https://doi. org/10.3389/fendo.2011.00096)

35 Merchant TE, Kiehna EN, Sanford RA, Mulhern RK, Thompson SJ, Wilson MW, Lustig RH \& Kun LE. Craniopharyngioma: the St. Jude Children's Research Hospital experience 1984-2001. International Journal of Radiation Oncology, Biology, Physics 200253 533-542. (https://doi.org/10.1016/S0360-3016(02)02799-2)

36 Muller HL, Bueb K, Bartels U, Roth C, Harz K, Graf N, Korinthenberg R, Bettendorf M, Kühl J, Gutjahr P, et al. Obesity after childhood craniopharyngioma - German multicenter study on preoperative risk factors and quality of life. Klinische Padiatrie 2001213 244-249. (https://doi.org/10.1055/s-2001-16855)

37 Muller HL, Emser A, Faldum A, Bruhnken G, Etavard-Gorris N, Gebhardt U, Oeverink R, Kolb R \& Sörensen N. Longitudinal study on growth and body mass index before and after diagnosis of childhood craniopharyngioma. Journal of Clinical Endocrinology and Metabolism 200489 3298-3305. (https://doi.org/10.1210/jc.2003031751)

38 Holmer H, Pozarek G, Wirfalt E, Popovic V, Ekman B, Bjork J \& Erfurth EM. Reduced energy expenditure and impaired feedingrelated signals but not high energy intake reinforces hypothalamic obesity in adults with childhood onset craniopharyngioma. Journal of Clinical Endocrinology and Metabolism 201095 5395-5402. (https:// doi.org/10.1210/jc.2010-0993)

39 Sorva R. Children with craniopharyngioma. Early growth failure and rapid postoperative weight gain. Acta Paediatrica Scandinavica 1988 77 587-592. (https://doi.org/10.1111/j.1651-2227.1988.tb10705.x) https://ec.bioscientifica.com https://doi.org/10.1530/EC-19-0074 (c) 2019 The authors Published by Bioscientifica Ltd
This work is licensed under a Creative Commons Attribution-NonCommercial-NoDerivatives 4.0 enternational License.ifica com at $04 / 26 / 2023$ 10:15:41AM 
40 Lustig RH. Hypothalamic obesity after craniopharyngioma: mechanisms, diagnosis, and treatment. Frontiers in Endocrinology 20112 60. (https://doi.org/10.3389/fendo.2011.00060)

41 Lustig RH, Hinds PS, Ringwald-Smith K, Christensen RK, Kaste SC, Schreiber RE, Rai SN, Lensing SY, Wu S \& Xiong X. Octreotide therapy of pediatric hypothalamic obesity: a double-blind, placebocontrolled trial. Journal of Clinical Endocrinology and Metabolism 2003 88 2586-2592. (https://doi.org/10.1210/jc.2002-030003)

42 Bereket A, Kiess W, Lustig RH, Muller HL, Goldstone AP, Weiss R, Yavuz Y \& Hochberg Z. Hypothalamic obesity in children. Obesity Reviews 201213 780-798. (https://doi.org/10.1111/j.1467789X.2012.01004.x)

43 Hochberg I \& Hochberg Z. Hypothalamic obesity. Endocrine Development 201017 185-196. (https://doi.org/10.1159/000262539)

44 Morton GJ, Cummings DE, Baskin DG, Barsh GS \& Schwartz MW. Central nervous system control of food intake and body weight. Nature 2006443 289-295. (https://doi.org/10.1038/nature05026)

45 Daousi C, Dunn AJ, Foy PM, MacFarlane IA \& Pinkney JH. Endocrine and neuroanatomic features associated with weight gain and obesity in adult patients with hypothalamic damage. American Journal of Medicine 2005118 45-50. (https://doi.org/10.1016/j. amjmed.2004.06.035)
46 Roth CL. Hypothalamic obesity in craniopharyngioma patients: disturbed energy homeostasis related to extent of hypothalamic damage and its implication for obesity intervention. Journal of Clinical Medicine 20154 1774-1797. (https://doi.org/10.3390/ jcm4091774)

47 Roth CL, Eslamy H, Werny D, Elfers C, Shaffer ML, Pihoker C, Ojemann J \& Dobyns WB. Semiquantitative analysis of hypothalamic damage on MRI predicts risk for hypothalamic obesity. Obesity 201523 1226-1233. (https://doi.org/10.1002/oby.21067)

48 Harz KJ, Muller HL, Waldeck E, Pudel V \& Roth C. Obesity in patients with craniopharyngioma: assessment of food intake and movement counts indicating physical activity. Journal of Clinical Endocrinology and Metabolism 200388 5227-5231. (https://doi.org/10.1210/ jc.2002-021797)

49 Roth CL, Blevins JE, Ralston M, Elfers C, Ogimoto K, Kaiyala KJ \& Morton GJ. A novel rodent model that mimics the metabolic sequelae of obese craniopharyngioma patients. Pediatric Research 201169 230-236. (https://doi.org/10.1203/ PDR.0b013e3182083b67)

50 Muller HL. Preoperative staging in childhood craniopharyngioma: standardization as a first step towards improved outcome. Endocrine 201651 1-3. (https://doi.org/10.1007/s12020-015-0800-x)

Received in final form 19 March 2019

Accepted 29 March 2019

Accepted Preprint published online 29 March 2019 (c) 2019 The authors Published by Bioscientifica Ltd
This work is licensed under a Creative Commons Attribution-NonCommercial-NoDerivatives 4.0 Internationab sicense.ifica . com at 04/26/2023 10:15:41AM 